\title{
The rs1893217 (T/C) polymorphism in PTPN2 gene is not associated with type 1 diabetes mellitus in subjects from Southern Brazil
}

\author{
O polimorfismo rs 1893217 (T/C) no gene PTPN2 não está \\ associado com diabetes melito em indivíduos do Sul do Brasil
}

Jakeline Rheinheimer, ${ }^{1,2}$, Fernanda dos Santos de Oliveira', Luís Henrique Canani ${ }^{2}$, Daisy Crispim ${ }^{1,2}$

\author{
${ }^{1}$ Laboratory of Biology of Human \\ Pancreatic Islets, Endocrine \\ Division, Hospital de Clínicas \\ de Porto Alegre (HCPA) \\ Porto Alegre, RS, Brazil \\ 2 Post-Graduation Program in \\ Medical Sciences: Endocrinology, \\ Federal University of Rio \\ Grande do Sul (UFRGS), \\ Porto Alegre, RS, Brazil
}

\begin{abstract}
Objective: To evaluate the association of the PTPN2 rs1893217 polymorphism with T1DM and/ or its clinical and laboratory characteristics in a Caucasian population from Southern Brazil. Subjects and methods: Four hundred and eighty six patients with T1DM and 484 non-diabetic subjects were included in the study. Genotyping of the PTPN2 rs1893217 was performed by real-time PCR. Results: Genotype frequencies did not differ between T1DM patients and non-diabetic subjects $(P=0.265)$. The $C$ allele was observed in $14.5 \%$ of the T1DM sample and $12.2 \%$ of the non-diabetic group $(P=0.152)$. Moreover, the frequencies of this variant did not differ statistically between T1DM patients and non-diabetic subjects when assuming recessive, dominant, or additive inheritance models. The clinical and laboratory characteristics of T1DM patients did not differ significantly among the three genotypes of the rs1893217 polymorphism, either. Conclusion: The PTPN2 rs1893217 polymorphism is not significantly associated with T1DM in Caucasian subjects from Southern Brazil. Arq Bras Endocrinol Metab. 2014;58(4):382-8
\end{abstract}

Keywords

Type 1 diabetes mellitus; polymorphism; PTPN2 gene; rs1893217

\section{RESUMO}

Correspondence to: Daisy Crispim

Endocrine Division

Hospital de Clínicas de Porto Alegre Rua Ramiro Barcelos, 2350,

Prédio $12,4^{\circ}$ andar

90035-003 - Porto Alegre, RS, Brazil

daisy_crispim@hotmail.com3

Received on Oct/7/2013

Accepted on Dec/28/2013

DOI: $10.1590 / 0004-2730000003050$
Objetivo: Avaliar a associação do polimorfismo rs1893217 no gene PTPN2 com DM1 e/ou suas características clínicas e laboratoriais em uma população de brancos do Sul do Brasil. Sujeitos e métodos: Quatrocentos e oitenta e seis pacientes com DM1 e 484 indivíduos não diabéticos foram incluídos no estudo. A genotipagem do PTPN2 rs1893217 foi realizada por PCR em tempo real. Resultados: As frequências genotípicas não diferiram entre os pacientes com DM1 e indivíduos não diabéticos $(p=0,265)$. $O$ alelo $C$ foi observado em $14,5 \%$ da amostra com DM1 e $12,2 \%$ no grupo de não diabéticos $(p=0,152)$. Além disso, as frequências dessa variante não diferiram estatisticamente entre os pacientes com DM1 e indivíduos não diabéticos considerando-se os modelos de herança recessivo, dominante ou aditivo. As características clínicas e laboratoriais dos pacientes com DM1 também não diferiram significativamente entre os três genótipos do polimorfismo rs1893217. Conclusão: O polimorfismo rs1893217 do gene PTPN2 não está associado com DM1 em brancos do Sul do Brasil. Arq Bras Endocrinol Metab. 2014;58(4):382-8

Descritores

Diabetes tipo 1; polimorfismo; gene PTPN2, rs1893217 


\section{INTRODUCTION}

$\mathrm{T}$ ype 1 diabetes mellitus (TIDM) is a complex disease resulting from a cellular-mediated autoimmune destruction of pancreatic beta-cells, rendering patients insulin-dependent for life (1). Destruction of beta-cells arises from the interplay of multiple genetic and environmental risk factors, which are still poorly defined $(2,3)$. The major susceptibility locus maps to the HLA class $I I$ genes $(\mathrm{OR}>6)$ at chromosome $6 \mathrm{p} 21$, and accounts for $30-50 \%$ of the genetic risk for the condition (4). Genome-wide association studies allowed the identification of several non-HLA loci with smaller effects on the genetic predisposition for TIDM (2), including the insulin gene, the CTLA4 gene, the IL2RA gene, the IFIH1 gene, the PTPN22 gene, and the PTPN2 (protein tyrosine phosphatase N2) gene $(5,6)$.

There is substantial evidence that viral pathogens, such as enteroviruses, play a major role in triggering the autoimmune destruction of pancreatic beta-cells (3). Type 1 interferons (IFNs) are important cytokines of the host immune response against viral infections (7). In addition to antiviral responses, these cytokines are able to induce apoptosis and to promote systemic autoimmunity (8). To control these effects of IFNs, organisms have developed several negative regulators of the IFN responses, and one of these regulators is PTPN2 (9).

The PTPN2 gene is located on chromosome 18 and encodes a phosphatase that is a member of the first nontransmembrane $(\mathrm{NTl})$ subfamily of protein tyrosine phosphatases (10). PTPN2 functions as a negative regulator of several signaling pathways, including Janus kinases (JAKs), signal transducer and activator of transcription (STATs), p42/44 MAPK (ERK) and epidermal growth factor receptor and insulin receptor $\beta$, also modulating beta-cell apoptosis induced by $\operatorname{IFN}-\gamma(11,12)$. Moreover, PTPN2 knockdown induces aberrant pro-apoptotic activity of the $\mathrm{BH} 3$-only protein Bim, resulting in increased apoptosis via JNK activation and the intrinsic apoptotic pathway in INS-1E, primary rat, and human beta-cells treated with type I or type II IFNs (13).

The Wellcome Trust Case Control Consortium (WTCCC) genome-wide association study reported an association of the rs2542151 single-nucleotide polymorphism (SNP), located $5.5 \mathrm{~kb}$ upstream of the PTPN2 gene, with three autoimmune diseases: Crohn's disease, rheumatoid arthritis, and TIDM (14). Todd and cols. (5) performed a follow-up study with the aim of replicating the WTCCC results on TIDM. The authors analyzed 11 SNPs within the disequilibrium block that contains the PTPN2 gene, and reported that two of them, rs478582 in intron 3, and rs1893217 in intron 7, were independently associated with TIDM. Moreover, the rs1893217 SNP was in strong linkage disequilibrium with rs2542151 SNP (5). In addition, Long and cols. (15) showed that the $\mathrm{C}$ allele of the rs 1893217 SNP is associated with decreased PTPN2 expression in $\mathrm{CD}^{+} \mathrm{T}$ cells. Therefore, the aim of this study was to replicate the reported association between the rs1893217 SNP and TIDM in an independent population from Southern Brazil.

\section{SUBJECTS AND METHODS}

\section{Subjects and phenotype measurements}

This was a case-control study designed to investigate whether the PTPN2 rs1893217 SNP is associated with TIDM. The diabetic sample comprised 486 unrelated patients from the outpatient clinic at the Hospital de Clínicas de Porto Alegre (Rio Grande do Sul, Brazil). Patients were considered to have TIDM if they had been diagnosed with hyperglycemia before the age of 30 years, required insulin for glycemic control within 1 year of diagnosis, and this treatment could not be interrupted thereafter (1). The non-diabetic sample comprised 484 healthy blood donors who did not have diabetes mellitus or family history of this disease (mean age $=40.0 \pm 7.8$; male $=50.0 \%$ ). All subjects were Caucasian Brazilians, and the ethnic group was self-reported.

All TIDM patients underwent physical and laboratory evaluations. They were weighed barefoot, wearing light outdoor clothes, and their height was measured as well. Body mass index (BMI) was calculated as weight $(\mathrm{kg}) /$ height (in meters) squared. Blood pressure (BP) was measured by a trained researcher with a mercury sphygmomanometer (Korotkoff phases I and V) using an appropriated cuff size, on the left arm of the patient in a sitting position, after a 5 -min rest. The mean of two measurements taken 1 min apart was used to calculate systolic and diastolic BP. Arterial hypertension $(\mathrm{AH})$ was defined as BP levels higher than 140/90 $\mathrm{mmHg}$ at the initial visit, and at two follow-up visits within 1 month of the initial visit, or if the presence of $\mathrm{AH}$ was registered on the medical records. Assessment of diabetic retinopathy (DR) was performed in all patients by an experienced ophthalmologist using fun- 
doscopy through dilated pupils. DR was classified using the scale developed by the Global Diabetic Retinopathy Group (16). For the purpose of this study, patients were grouped according to the presence or absence of any degree of DR. Diagnosis of diabetic nephropathy (DN) was based on the albumin excretion rate (AER) in at least two out of three consecutive 24-h timed or random spot sterile urine collections in a 6-month period. Patients were classified as having normoalbuminuria (AER $<30 \mu \mathrm{g} / 24 \mathrm{~h}$ or $<17 \mathrm{mg} / \mathrm{L}$ ), microalbuminuria (AER 30-299 $\mu \mathrm{g} / 24 \mathrm{~h}$ or $17-173 \mathrm{mg} / \mathrm{L}$ ) or macroalbuminuria $($ AER $>300 \mu \mathrm{g} / 24 \mathrm{~h}$ or $>174 \mathrm{mg} / \mathrm{L})(17)$.

Serum and plasma samples were taken after 12 hours of fasting for laboratory analyses. Plasma glucose levels were determined using the glucose oxidase method. Creatinine levels were determined using the Jaffe reaction. Glycated hemoglobin (HbAlc) measurements were performed by different methods, and results were traceable to the DCCT method. Total plasma cholesterol, HDL cholesterol, and triglycerides were assayed using enzymatic methods. Urinary albumin was measured by immunoturbidimetry (Microalb; Ames-Bayer, Tarrytown NY), and intra- and interassay coefficients of variation in our laboratory were both $<6 \%$. The research protocol was approved by the Hospital ethics committee, and all subjects signed an informed consent form.

\section{Genotyping}

DNA was extracted from peripheral blood leukocytes using a standardized salting-out procedure. The PTPN2 rs1893217 SNP was genotyped using primers and probes contained in the Human Custom TaqMan Genotyping Assay 20x (Assays-By-Design Service; Life Technologies, Foster City, CA). Sequences of primers and probes were: 5' GGCCCAGATACACTCTTCTTCCT 3' (forward); 5' TGTGCTCTCACTTGTCACCATT 3' (reverse); 5' CCTAGGGACAGAGGTAG 3' (VIC) and 5' CTAGGGACAAAGGTAG 3' (FAM). Reactions were conducted in 96-well plates, in a total $5 \mu \mathrm{L}$ volume using 2 ng of genomic DNA, TaqMan Genotyping Master Mix lx (Life Technologies) and Custom TaqMan Genotyping Assay lx. The plates were then positioned in a thermal cycler (7500 Fast Real-Time PCR System; Life Technologies), and heated for $10 \mathrm{~min}$ at $95^{\circ} \mathrm{C}$, followed by 50 cycles of $95^{\circ} \mathrm{C}$ for $15 \mathrm{~s}$ and $63^{\circ} \mathrm{C}$ for $1 \mathrm{~min}$. The genotyping success rate was greater than $95 \%$, with a calculated error rate based on PCR duplicates of less than $1 \%$.

\section{Statistical analysis}

Allelic frequencies were determined by gene counting, and departures from the Hardy-Weinberg equilibrium (HWE) were verified using $\chi^{2}$-tests. Allele and genotype frequencies were compared between groups of patients using $\chi^{2}$-tests. Clinical and laboratory characteristics were compared among groups using One-way ANOVA, Student's t-test or $\chi^{2}$, as appropriate. In addition, General Linear Model (GLM) analyses were performed for comparing clinical and laboratory characteristics among genotypes adjusting for possible confounding factors. Variables with normal distribution are presented as mean \pm SD or percentages. Variables with skewed distribution were $\log$-transformed before analyses and are presented as medians (minimum-maximum values). The magnitude of associations between rs1893217 SNP and TIDM assuming different inheritance models were estimated using odds ratios (OR) with 95\% CI.

Results for which P was less than 0.05 were considered statistically significant. Bonferroni corrections were used to account for multiple comparisons. These statistical analyses were performed using SPSS version 18.0 (SPSS, Chicago, IL). Power calculations (PEPI program, version 4.0) showed that this study has a power of approximately $80 \%$ at a significance level of 0.05 to detect an odds ratio of 1.65 (for the presence of the $\mathrm{C}$ allele).

\section{RESULTS}

The main clinical and laboratory characteristics of the 486 TIDM patients belonging to the present study were as follows: mean age was $33.9 \pm 13.1$ years; mean age at TIDM diagnosis was $17.3 \pm 10.1$ years, mean HbAlc was $9.1 \pm 5.6 \%$, and mean BMI was $23.1 \pm 4.8$ $\mathrm{kg} / \mathrm{m}^{2}$. Males comprised $49.4 \%$ of the sample, $27.8 \%$ of all patients had $\mathrm{AH}, 43.0 \%$ had some degree of $\mathrm{DR}$, and $32.3 \%$ had some degree of DN.

Genotype and allele frequencies of the PTPN2 rs1893217 SNP (T/C) polymorphism in TIDM patients and non-diabetic subjects are depicted in table 1 . Genotype frequencies of the rs1893217 SNP did not differ significantly between TIDM patients and non-diabetic subjects $(P=0.265)$, and they were in agreement with those predicted by the HWE in the two samples $(\mathrm{P}>0.05)$. In the same way, the minor allele $(\mathrm{C})$ of the rs1893217 SNP was similarly distributed between diabetic patients and non-diabetic subjects $(14.2 \%$ vs. $12.2 \%$, respectively; $\mathrm{P}=0.152$ ). The frequencies of this 
Table 1. Genotype and allele frequencies of the PTPN2 rs1893217 T/C polymorphism in patients with type 1 diabetes mellitus (T1DM) and nondiabetic subjects

\begin{tabular}{lccc}
\hline & $\begin{array}{c}\text { T1DM patients } \\
(\mathbf{n}=\mathbf{4 8 6 )}\end{array}$ & $\begin{array}{c}\text { Non-diabetic } \\
\text { subjects } \\
(\mathbf{n = 4 8 4 )}\end{array}$ & P value* $^{*}$ \\
\hline Genotype & $357(73.5 \%)$ & $377(77.9 \%)$ & \\
T/T & $117(24.0 \%)$ & $96(19.8 \%)$ & 0.265 \\
T/C & $12(2.5 \%)$ & $11(2.3 \%)$ & \\
C/C & & & \\
Allele & 0.855 & 0.878 & 0.152 \\
T & 0.145 & 0.122 & \\
C & & & \\
Recessive model & $12(2.5 \%)$ & $11(2.3 \%)$ & 0.99 \\
C/C & $474(97.5 \%)$ & $473(97.7 \%)$ & \\
T/C - T/T & & & \\
Dominant model & $129(26.5 \%)$ & $107(22.1 \%)$ & 0.125 \\
T/C - C/C & $357(73.5 \%)$ & $377(77.9 \%)$ & \\
TT & & & 0.903 \\
Additive model & $12(3.2 \%)$ & $11(2.8 \%)$ & \\
C/C & $357(96.8 \%)$ & $377(97.2 \%)$ & \\
T/T & & & \\
\hline
\end{tabular}

Data are presented as numbers (\%) or proportions. ${ }^{*} \mathrm{P}$ values were computed by $\chi^{2}$ tests comparing T1DM patients and non-diabetic subjects. Only $\mathrm{P}$ values lower than the Bonferroni threshold $[P=0.01(0.05 / 5$ comparisons)] were considered statistically significant. variant also did not differ statistically between TIDM patients and non-diabetic subjects when assuming different genetic inheritance models: recessive $(\mathrm{T} / \mathrm{C}+$ $\mathrm{T} / \mathrm{T}$ vs. $\mathrm{C} / \mathrm{C})$, dominant $(\mathrm{T} / \mathrm{T}$ vs. $\mathrm{T} / \mathrm{C}+\mathrm{C} / \mathrm{C})$, or additive $(\mathrm{C} / \mathrm{C} v s . \mathrm{T} / \mathrm{T})$ (Table $\mathrm{l})$.

Clinical and laboratory characteristics of TIDM patients broken down by the different genotypes of the rs1893217 SNP are shown in table 2. Mean age, proportion of males and age at TIDM diagnosis were similar among the different genotype of the rs 1893217 SNP $(\mathrm{P}=0.323, \mathrm{P}=0.164$, and $\mathrm{P}=0.182$, respectively). Moreover, BMI, lipid and glucose profile, creatinine levels, systolic and diastolic BP, and presence of DR and DN also did not differ statistically among the three genotypes (Table 2). Clinical and laboratory characteristics of TIDM patients according to the presence of the minor allele (C) of the rs1893217 SNP (dominant model) are shown in table 3. In agreement with genotype data, none of these characteristics differed between patients carrying the $\mathrm{C}$ allele as compared with patients with the $\mathrm{T} / \mathrm{T}$ genotype (Table 3 ). These characteristics were not compared using other inheritance model due to the small number of subjects carrying the $\mathrm{C} / \mathrm{C}$ genotype $(\mathrm{n}=12)$.

Table 2. Clinical and laboratory characteristics of patients with type 1 diabetes mellitus broken down by the different genotypes of the PTPN2 rs1893217 (T/C) polymorphism

\begin{tabular}{|c|c|c|c|c|}
\hline \multicolumn{5}{|c|}{ PTPN2 rs1893217 (T/C) polymorphism } \\
\hline & $T / T(n=357)$ & $T / C(n=117)$ & $C / C(n=12)$ & $\mathbf{P}^{*}$ \\
\hline Age (years) & $33.5 \pm 11.8$ & $35.8 \pm 17.9$ & $40.0 \pm 13.9$ & 0.323 \\
\hline Gender (\% male) & 54.4 & 44.3 & 54.5 & 0.164 \\
\hline Age of diagnosis (years) & $16.8 \pm 10.0$ & $15.7 \pm 9.0$ & $23.3 \pm 12.9$ & 0.182 \\
\hline $\mathrm{BMI}\left(\mathrm{kg} / \mathrm{m}^{2}\right)$ & $23.0 \pm 5.1$ & $24.0 \pm 3.4$ & $21.1 \pm 5.7$ & 0.256 \\
\hline Systolic BP (mmHg) & $121.1 \pm 17.3$ & $123.3 \pm 20.7$ & $116.0 \pm 11.5$ & 0.500 \\
\hline Diastolic BP (mmHg) & $78.0 \pm 11.6$ & $78.0 \pm 13.1$ & $71.4 \pm 12.1$ & 0.357 \\
\hline HDL cholesterol (mmol/L) & $1.45 \pm 0.45$ & $1.49 \pm 0.53$ & $1.51 \pm 0,38$ & 0.950 \\
\hline Total cholesterol (mmol/L) & $4.72 \pm 1.29$ & $4.60 \pm 0.97$ & $4.23 \pm 0.70$ & 0.362 \\
\hline Triglycerides (mmol/L) & $0.85(0.28-10.16)$ & $0.92(0.28-6.02)$ & $0.66(0.36-5.72)$ & 0.680 \\
\hline Creatinine $(\mu \mathrm{mol} / \mathrm{L})$ & $88.4(35.36-981.24)$ & $88.4(44.12-934.0)$ & $79.56(53.04-247.52)$ & 0.605 \\
\hline HbA1c (\%) & $8.9 \pm 4.9$ & $8.6 \pm 2.2$ & $8.7 \pm 1.3$ & 0.907 \\
\hline Diabetic nephropathy (\%) & 30.2 & 28.0 & 33.3 & 0.939 \\
\hline Diabetic retinopathy (\%) & 43.2 & 47.5 & 30.0 & 0.525 \\
\hline
\end{tabular}

Data are presented as means \pm SD, medians (minimum-maximum values) or $\%$. BMl, body mass index; BP $=$ blood pressure. HbA1c $=$ glycohemoglobin. ${ }^{*} \mathrm{P}$ values were obtained using $\chi^{2}$ or ANOVA tests, as appropriate. Only $\mathrm{P}$ values lower than the Bonferroni threshold $[\mathrm{P}=0.0038(0.05 / 13$ comparisons)] were considered statistically significant. 
Table 3. Clinical and laboratory characteristics of patients with type 1 diabetes mellitus, broken down by the presence of the minor allele (C) of the PTPN2 rs1893217 (T/C) polymorphism

\begin{tabular}{|c|c|c|c|}
\hline \multicolumn{4}{|c|}{ PTPN2 rs1893217 (T/C) polymorphism } \\
\hline & $T / T(n=357)$ & $T / C-C / C(n=129)$ & P value \\
\hline Age (years) & $33.5 \pm 11.8$ & $36.2 \pm 17.5$ & 0.186 \\
\hline Gender (\% male) & 54.4 & 44.4 & 0.099 \\
\hline Age at diagnosis (years) & $16.8 \pm 9.9$ & $16.4 \pm 9.6$ & 0.758 \\
\hline $\mathrm{BMl}\left(\mathrm{kg} / \mathrm{m}^{2}\right)$ & $23.0 \pm 5.1$ & $23.6 \pm 3.8$ & 0.381 \\
\hline Systolic BP (mm/Hg) & $121.1 \pm 17.3$ & $122.6 \pm 20.0$ & 0.553 \\
\hline Diastolic BP (mm/Hg) & $78.0 \pm 11.6$ & $77.4 \pm 13.0$ & 0.718 \\
\hline HDL cholesterol (mmol/L) & $1.45 \pm 0.45$ & $1.50 \pm 0.51$ & 0.757 \\
\hline Total cholesterol (mmol/L) & $4.72 \pm 1.29$ & $4.54 \pm 0.95$ & 0.237 \\
\hline Triglycerides (mmol/L) & $0.85(0.28-10.16)$ & $0.86(0.28-6.48)$ & 0.421 \\
\hline Creatinine $(\mu \mathrm{mol} / \mathrm{L})$ & $88.4(35.36-981.24)$ & $88.4(44.2-937.04)$ & 0.419 \\
\hline HbA1c (\%) & $8.9 \pm 4.9$ & $8.6 \pm 2.1$ & 0.660 \\
\hline Diabetic nephropathy (\%) & 30.2 & 28.6 & 0.953 \\
\hline Diabetic retinopathy (\%) & 43.2 & 45.6 & 0.789 \\
\hline
\end{tabular}

Data are means $\pm S D$, medians (minimum-maximum values) or \%. BMl: body mass index. BP: blood pressure. HbA1c: glycohemoglobin. ${ }^{*} P$ values obtained from Student's t-tests. Only P values lower than the Bonferroni threshold $[\mathrm{P}=0.0038(0.05 / 13$ comparisons)] were considered statistically significant.

\section{DISCUSSION}

PTPN2 gene is expressed in several cell types, including beta-cells, intestinal epithelial cells, and immune cells (12). Transfection with siRNAs against PTPN2 inhibits basal and cytokine-induced PTPN2 expression in rat beta-cells and dispersed human islet cells. Decreased PTPN2 expression exacerbates IL-1 $\beta+$ IFN- $\gamma$-induced beta-cell apoptosis and turns IFN- $\gamma$ alone into a proapoptotic signal. Moreover, inhibition of PTPN2 amplifies IFN- $\gamma$-induced STAT-1 phosphorylation, whereas double knockdown of both PTPN2 and STAT-1 protects beta-cells against cytokine-induced apoptosis, suggesting that STAT-1 hyperactivation is responsible for the aggravation of cytokine-induced beta-cell death in PTPN2-deficient cells (12). Therefore, PTPN2 may contribute to the pathogenesis of TIDM since changes in PTPN2 function in beta-cells sensitize these cells to pro-apoptotic inflammatory signals, potentially amplifying beta-cell loss and insulitis, independent of its potential effects on the immune system (12).

In agreement with a potentially important role of PTPN2 in T1DM pathogenesis, genome-wide association studies have reported an association between PTPN2 polymorphisms and T1DM $(2,5,14)$. However, in the present case-control study, we were not able to replicate the reported association of the rs1893217 SNP in the PTPN2 gene with TIDM in Caucasian Bra- zilians. One possible explanation for the discrepant results is that most of TIDM studies selected their sample population limiting the age at TIDM onset to less than 17 years to avoid including type 2 diabetes misdiagnosed patients. This was the strategy used for the above mentioned genome-wide scan studies, but it was not an exclusion criteria used in our study since the mean age at diagnosis of our patients was $17.3 \pm 10.1$ years. We decided not exclude patients with age of onset higher than 17 years because TIDM diagnosis may happen at any age; thus, excluding this group of patients could prevent us from determining the possible different genetic background between early and late-onset TIDM subgroups. In this context, Espino-Paisan and cols. (18) showed that the frequency of the rs $2542151 \mathrm{G}$ allele of the PTPN2 gene was significantly higher in an early-TIDM onset group (onset before 16 years) compared with late-onset TIDM patients and controls (OR $=1.61 ; 95 \%$ CI 1.14-2.26). No significant differences were found between controls and late-onset group. It is worth noting that, in the present study, the frequencies of the PTPN2 rs1893217 SNP were similar between early- and late-TIDM onset patients $(\mathrm{P}>0.05)$; therefore, age of TIDM onset might not have influenced our results.

As already mentioned, the strongest genetic association for TIDM is with the HLA class II genes (4). Consequently, cohort studies following children 
with high-risk HLA genotypes to islet autoimmunity and TIDM development offers a valuable tool to further validate the independent predictive value of non-HLA loci and to explore the genetic architecture of TIDM in different populations. Steck and cols. (6) assessed the effects of 20 non-HLA gene polymorphisms on the risk of islet autoimmunity and progression to TIDM in the Diabetes Autoimmunity Study in the Young (DAISY). Interestingly, they observed that the PTPN2 rs1893217 SNP predicted islet autoimmunity [Hazard ratio (HR) 1.42, 95\% CI 1.02-1.99] but not TIDM development, after controlling for family history of TIDM and HLA high-risk genotypes (6). The absence of association with TIDM is in agreement with the present study. Unfortunately, we did not evaluate HLA high-risk genotypes in our population to know if this genetic background would modify our results.

Interactions with non-HLA genes also might influence the effects of the PTPN2 rs1893217 SNP on TIDM risk. For example, Frederiksen and cols. (19) reported an interaction between vitamin D receptor (VDR) and PTPN2 genes on the progression to TIDM in children from the DAISY cohort: in children with the PTPN2 rs1893217 A/A genotype, the VDR rs1544410 A allele was associated with a decreased risk of TIDM $(\mathrm{HR}=0.24,95 \% \mathrm{CI} 0.11-0.53)$, while in children with the PTPN2 rs1893217 G allele, the VDR rs1544410 A allele was not associated with this disease. This interaction has biological plausibility, since the VDR binds to a novel intronic binding site in the PTPN2 gene (20), and suggests that variations in both $V D R$ and PTPN2 genes are necessary to lead to an effect on TIDM risk.

Some factors unrelated to the PTPN2 rs1893217 SNP could have interfered with the findings of the present study. First, we cannot rule out the possibility of population stratification bias when analyzing our samples, even though only Caucasian-Brazilian subjects were studied and both TIDM patients and non-diabetic subjects were recruited from the same hospital, thus reducing the risk of false positive/negative associations due to this bias. Second, we cannot fully exclude the possibility of a type II error when analyzing the association between the PTPN2 rs1893217 SNP and T1DM. Power calculations were based on OR of 1.65 for the presence of the $\mathrm{C}$ allele; however, we had less than $80 \%$ power to detect $\mathrm{OR} \leq 1.65$, which is the case for most of the TIDM-related genes (5). Third, interactions of the analyzed polymorphism with other important characteristics, such as islet autoantibodies and HLA high-risk genotypes could have influenced our results; unfortunately, we do not have information about these covariates in our sample.

In conclusion, the present study found no evidence for a significant association between the rs1893217 SNP in the PTPN2 gene and TIDM. Further multicenter studies including larger sample numbers and analyzing gene-gene interactions are necessary to confirm these results in the Brazilian population. Furthermore, prospective studies following children since islet autoimmunity development to progression to TIDM are also necessary, as they may offer additional insights concerning the association of PTPN2 and other TIDM-related genes with TIDM.

Acknowledgments: this study was supported by grants from the Fundação de Amparo à Pesquisa do Estado do Rio Grande do Sul (Fapergs), Conselho Nacional de Desenvolvimento Científico e Tecnológico (CNPq), Coordenação de Aperfeiçoamento de Pessoal de Nível Superior (Capes) and Fundo de Incentivo à Pesquisa e Eventos (Fipe) at Hospital de Clínicas de Porto Alegre. Daisy Crispim was a recipient of a CNPq grant.

Disclosure: no potential conflict of interest relevant to this article was reported.

\section{REFERENCES}

1. ADA (American Diabetes Association). Diagnosis and classification of diabetes mellitus. Diabetes Care. 2013;36 Suppl 1:S67-74.

2. Barrett JC, Clayton DG, Concannon P, Akolkar B, Cooper JD, Erlich $\mathrm{HA}$, et al. Genome-wide association study and meta-analysis find that over 40 loci affect risk of type 1 diabetes. Nat Genet. 2009;41(6):703-7.

3. Hober D, Sauter P. Pathogenesis of type 1 diabetes mellitus: interplay between enterovirus and host. Nat Rev Endocrinol. 2010;6(5):279-89.

4. Noble JA, Valdes AM, Cook M, Klitz W, Thomson G, Erlich HA. The role of HLA class II genes in insulin-dependent diabetes mellitus: molecular analysis of 180 Caucasian, multiplex families. Am J Hum Genet. 1996;59(5):1134-48.

5. Todd JA, Walker NM, Cooper JD, Smyth DJ, Downes K, Plagnol $\mathrm{V}$, et al. Robust associations of four new chromosome regions from genome-wide analyses of type 1 diabetes. Nat Genet. 2007;39(7):857-64.

6. Steck AK, Wong R, Wagner B, Johnson K, Liu E, Romanos J, et al. Effects of non-HLA gene polymorphisms on development of islet autoimmunity and type 1 diabetes in a population with high-risk HLA-DR,DQ genotypes. Diabetes. 2012;61(3):753-8.

7. Randall RE, Goodbourn S. Interferons and viruses: an interplay between induction, signalling, antiviral responses and virus countermeasures. J Gen Virol. 2008;89(Pt 1):1-47.

8. Baccala R, Hoebe K, Kono DH, Beutler B, Theofilopoulos AN. TLRdependent and TLR-independent pathways of type I interferon induction in systemic autoimmunity. Nat Med. 2007;13(5):543-51. 
9. Zhu W, Mustelin T, David M. Arginine methylation of STAT1 regulates its dephosphorylation by $T$ cell protein tyrosine phosphatase. J Biol Chem. 2002;277(39):35787-90.

10. Doody KM, Bourdeau A, Tremblay ML. T-cell protein tyrosine phosphatase is a key regulator in immune cell signaling: lessons from the knockout mouse model and implications in human disease. Immunol Rev. 2009;228(1):325-41.

11. ten Hoeve J, de Jesus Ibarra-Sanchez M, FuY, Zhu W, Tremblay M, David $\mathrm{M}$, et al. Identification of a nuclear Stat1 protein tyrosine phosphatase. Mol Cell Biol. 2002;22(16):5662-8.

12. Moore F, Colli ML, Cnop M, Esteve MI, Cardozo AK, Cunha DA, et al. PTPN2, a candidate gene for type 1 diabetes, modulates interferon-gamma-induced pancreatic beta-cell apoptosis. Diabetes. 2009;58(6):1283-91.

13. Santin I, Moore F, Colli ML, Gurzov EN, Marselli L, Marchetti P, et al. PTPN2, a candidate gene for type 1 diabetes, modulates pancreatic beta-cell apoptosis via regulation of the $\mathrm{BH} 3$-only protein Bim. Diabetes. 2011;60(12):3279-88.

14. WTCCC (WelcomeTrust Case Control Consortium). Genome-wide association study of 14,000 cases of seven common diseases and 3,000 shared controls. Nature. 2007;447(7145):661-78.

15. Long SA, Cerosaletti K, Wan JY, Ho JC, Tatum M, Wei S, et al. An autoimmune-associated variant in PTPN2 reveals an impairment of IL-2R signaling in CD4(+) T cells. Genes Immun. 2011;12(2): $116-25$.

16. Wilkinson $\mathrm{CP}$, Ferris $\mathrm{FL}$, 3rd, Klein RE, Lee PP, Agardh CD, Davis $M$, et al. Proposed international clinical diabetic retinopathy and diabetic macular edema disease severity scales. Ophthalmology. 2003;110(9):1677-82.

17. Molitch ME, DeFronzo RA, Franz MJ, Keane WF, Mogensen CE, Parving $\mathrm{HH}$, et al. Nephropathy in diabetes. Diabetes Care. 2004;27 Suppl 1:S79-83.

18. Espino-Paisan $L$, de la Calle $H$, Fernandez-Arquero $M$, Figueredo MA, de la Concha EG, Urcelay E, et al. A polymorphism in PTPN2 gene is associated with an earlier onset of type 1 diabetes. Immunogenetics. 2011;63(4):255-8.

19. Frederiksen B, Liu E, Romanos J, Steck AK, Yin X, Kroehl M, et al. Investigation of the vitamin $D$ receptor gene (VDR) and its interaction with protein tyrosine phosphatase, non-receptor type 2 gene (PTPN2) on risk of islet autoimmunity and type 1 diabetes: the Diabetes Autoimmunity Study in theYoung (DAISY). J Steroid Biochem Mol Biol. 2013;13351-7.

20. Ramagopalan SV, Heger A, Berlanga AJ, Maugeri NJ, Lincoln MR, Burrell A, et al. A ChIP-seq defined genome-wide map of vitamin $D$ receptor binding: associations with disease and evolution. Genome Res. 2010;20(10):1352-60. 